\title{
The use of membrane technology for the formulation of spent anaerobic digester effluents as a nutrient source for bacterial growth
}

\author{
M. P. Zacharof ${ }^{1,2}$, C. Vouzelaud ${ }^{1} \&$ R. W. Lovitt ${ }^{1,2}$ \\ ${ }^{1}$ Centre for Complex Fluid Processing (CCFP), College of Engineering, \\ Swansea University, UK \\ ${ }^{2}$ Centre for Water Advanced Technologies and Environmental Research \\ (CWATER), College of Engineering, Swansea University, UK
}

\begin{abstract}
Spent digester effluents were formulated into nutrient media, suitable for microbial growth of industrially important microorganisms, using filtration and diafiltration. The waste effluents were pretreated by dilution, sedimentation and sieving for the removal of large particulate material. The scheme used allowed the successful formulation particle, free sterile effluents, with an $\mathrm{N}: \mathrm{P}$ ratio 36.6 The prepared microfiltered effluents were then physicochemically characterized before being assessed for their utilization as growth substrates of microorganism associated with chemical and fuels production. Microfiltered treated digested propagated with Escherichia coli NCIMB 8277, agricultural sludge based media were compared with in vitro media when supplied with or without addition carbohydrate sources. in bench scale batch aerobic. Good growth was achieved compared to synthetic growth media with the microorganism using filtrates. When the treated effluents were supplied with $2 \%$ $\mathrm{w} / \mathrm{v}$ glucose solution a significant improvement in the growth rates and growth yields was achieved giving comparable performance with the synthetic media.

Keywords: microfiltration, anaerobic digestion, sludge, nutrient media, bacterial growth, biofuels, acid, wastewater treatment.
\end{abstract}




\section{Introduction}

Anaerobic digestion (AD) for the treatment and disposal of various genres of waste including domestic, municipal, agricultural and industrial is rapidly developing [1] throughout Northern Europe and United States. Utilising waste as a source of energy i.e. biogas production, platform chemicals, metals and other elements is becoming attractive [1]. It is now becoming evident in a resource limited world that there is considerable energy and valuable resources are embedded these materials [2].

Certainly, $\mathrm{AD}$ is minimising the volume of animal waste and other relevant agricultural waste such as silage and vegetative sources, and offers a strong alternative within the concept of green energy, there is a significant amount of wastewater and sludge produced; creating an environmental constraint that has to be solved [3].

These produced streams have been found high in dissolved carbon (organic acids), ammonia, phosphate, metal ions and other chemicals. However, regarding their complex physicochemical nature and the varying composition due to the changeable conditions of operation of anaerobic digestion plants, the economic separation and recovery of these substances from these streams is not a unequivocal process [4]. These effluents may often demand intensive pre-treatment to be further processible [5].

One alternative and possibly important use of the streams that could add monetary value is to use these as sources of nutrients for microbial growth so to generate energy either in the form of power or as fuels and platform chemicals [6]. There are numerous criteria that have to be met so to successfully utilise these materials as growth media. A paramount step is the removal of particulate matter and consequently sanitize the materials that can be stabilized and formulated to ensure efficient their utilization [7]. To achieve this, these streams have to be solubilised, fractionated, concentrated and reformulated [8].

Another aspect, that has not been extensively considered, is the fact that the solid fraction of the sludge is a repository of absorbed materials that can be removed by acid or other pre-treatments. Within this context, membrane filtration can offer feasible options towards an economical recovery, fractionation and concentration of these materials (Figure 1) providing many routes to valorise these materials [9].

Consequently this paper reports on the formulation of spent digester effluents into nutrient media, suitable for microbial growth of industrially important microorganisms, using filtration and diafiltration.

The waste effluents were pre-treated by dilution, sedimentation and sieving for the removal of large particulate material such as straw or stones prior to MF. The scheme used allowed the successful formulation particle, free sterile effluents, with an N:P ratio 36.6 [10]. The prepared microfiltered effluents were then physicochemically characterized before being assessed for their utilization as growth substrates of microorganism associated with chemical and fuels production. These formulated media were then used to assess the performance of Escherichia coli NCIMB 8277, in bench scale batch anaerobic cultures. Good 
growth was achieved compared to synthetic growth media with the microorganism using filtrates. When the treated effluents were supplied with $2 \%$ $\mathrm{w} / \mathrm{v}$ glucose solution a significant improvement in the growth rates and growth yields was achieved giving comparable performance with the synthetic media.

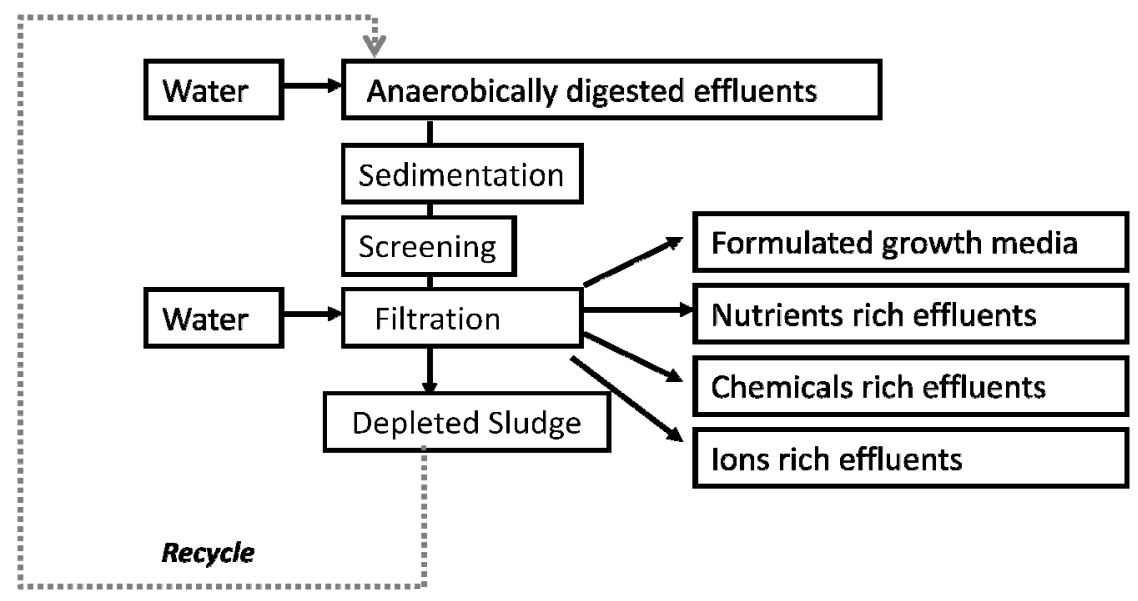

Figure 1: Processing and recovery scheme for anaerobically digested effluents.

\section{Materials and methods}

\subsection{Materials}

\subsubsection{Waste effluents}

Effluent streams samples from anaerobically digested spent animal faecal matter were used. The digested effluents $(25 \mathrm{~L})$, provided by Renewable Environmental Energy Limited (FRE), Wrexham, Wales, United Kingdom, were collected the output line of the sedimentation tank, prior to filtration [10].

\subsubsection{Effluents pre-treatment scheme}

The effluent was found comprising of coarse particles i.e. straw and other large particles. A pre-treatment scheme was developed to remove these, combining dilution with tap water $(50 \% \mathrm{v} / \mathrm{v})$, thorough manual mixing for one hour using a rod, twenty-four hour sedimentation in a settling tank and treatment of the supernatant with a series of coarse filters varying in pore size between $1.045 \mathrm{~mm}$ to $0.5 \mathrm{~mm}[9]$.

\subsubsection{Bacterial strain}

Escherichia coli NCIMB 8277 was provided in a lyophilised form by National Collection of Industrial Food and Marine bacteria (NCIMB), Aberdeen, Scotland, United Kingdom. The bacterium was revived twice by inoculating the 
selected strain into $50 \mathrm{ml}$ serum vials containing basal medium (Luria Bertani broth, LB) and were statically incubated at $37^{\circ} \mathrm{C}$ (Thermo Scientific Series 6000 Incubator, USA) for 24 hours. Stock culture solutions of each strain were made through cryopreservation method [11]. For constant use, the bacterium was regularly reinoculated (on a weekly basis) into $30 \mathrm{ml}$ serum vials containing basal medium and were preserved at $2^{\circ} \mathrm{C}[11]$.

\subsection{Methods}

\subsubsection{Microfiltration of agricultural sludge}

The filtration unit, equipped with a cross-flow Membralox ceramic filter element $\left(\alpha-\mathrm{Al}_{2} \mathrm{O}_{3}\right)$ - (pore size $0.2 \mu \mathrm{m}$, effective membrane area $0.22 \mathrm{~m}^{2}$ ) membrane, able to withstand a $\mathrm{pH}$ range between 0 to14, fitted in stainless steel module, commercially available from Axium Process (Hendy, Wales, UK), consisted of a $100 \mathrm{~L}$ stainless steel vessel linked via $5 \mathrm{~m}$ of 1 inch stainless steel piping arranged in two fluid loops each powered by a centrifugal pumps. A detailed description of the unit can be found elsewhere [10]. The pre-treated effluent was then processed through microfiltration unit

\subsubsection{Analysis of dry matter content and physicochemical characteristics}

Total solids (TS, g/L), total suspended solids (TSS, g/L), total dissolved solids (TDS), alkalinity, optical density, nitrogen measured as ammonia $\left(\mathrm{NH}_{3}-\mathrm{N}\right)$ and phosphorous $\left(\mathrm{PO}_{4}-\mathrm{P}\right)$ using the phenate and vanadomolybdo-phosphoric acid colorimetric methods were determined according to Standard Methods for the Examination of Water and Wastewater published by APHA, AWWA and WPCF 20th Edition, 1998. Volatile fatty acids (VFA) were determined using head space gas chromatography [9]. Each parameter was triplicated to obtain the average data (standard deviation of mean $<5 \%$, standard error $<7 \%$ ) offering highly significant results. Particle size distribution (PSD) of the sludge samples was determined by light scattering technique using Mastersizer 2000 (Malvern, UK), the zeta potential was determined by the Zetasizer (Malvern, UK), the conductivity and salinity of the samples were measured used a conductivity meter (Russell systems, UK) calibrated with a standard solution of $0.1 \mathrm{M}$ of $\mathrm{KCl}$.

\subsubsection{Growth on LB broth, minimised media and treated agricultural wastewater}

The specified quantities of powdered materials for LB medium, namely, yeast extract $5 \mathrm{~g} / \mathrm{L}$, bacteriological peptone (from poultry) $10 \mathrm{~g} / \mathrm{L}$, sodium chloride $10 \mathrm{~g} / \mathrm{L}$, were weighted into an electronic balance (Sartorius, CP4202S, JENCONS-PLS, Germany) and they are added into an Erlenmeyer flask containing $1 \mathrm{~L}$ of distilled water. Once mixed the medium ( $\mathrm{pH} 6.4)$ was decanted into $100 \mathrm{ml}$ aliquots were placed into $250 \mathrm{ml}$ Erlenmeyer flask. Once cooled, the flasks were sealed and secured with cotton and alumina foil and were autoclaved at $121^{\circ} \mathrm{C}$ for $15 \mathrm{~min}$. The same process was followed for the preparation of minimised media (tap water mixed with $2 \% \mathrm{w} / \mathrm{v}$ glucose in a $1: 1 \mathrm{ratio}$ ), treated agricultural wastewater and enriched agricultural with LB broth and $2 \% \mathrm{w} / \mathrm{v}$ 
glucose solution added in a 1:1 ratio. The flasks were gently mixed in a vortex and inoculated with $10 \mathrm{ml}$ inoculum size, and incubated in a rotary shaker at $37^{\circ} \mathrm{C}$ (Thermo Scientific Incubator, UK) at $37^{\circ} \mathrm{C}[11]$.

\subsubsection{Measurement of cellular growth and biomass}

The cellular growth was measured into a UV-Visible UNICAM UV300 dual beam spectrophotometer at $600 \mathrm{~nm}$. The tube had a $1 \mathrm{~cm}$. light path. Maximum specific growth rate $\left(\mu_{\max }, h^{-1}\right)$ [12] microbial strain were determined into the media under a 10 hour circle of static incubation into $37^{\circ} \mathrm{C}$ (Thermo Scientific Series 6000 Incubator, USA).

\section{Results and discussion}

The spent anaerobically digested effluents were treated consequently with dilution, thorough mixing and sedimentation. The resulting supernatant was collected using a series of sieves to ensure further removal of large particles and filtered into ceramic microfiltration unit. A significant reduction in solids content between the untreated spent digested effluent and the treated microfiltered permeate was achieved. For example, TS were reduced by $66 \%$ $(15.13 \mathrm{~g} / \mathrm{L}$ to $5.15 \mathrm{~g} / \mathrm{L})$, TSS were reduced by $69 \%(612 \mathrm{~g} / \mathrm{L}$ to $190 \mathrm{~g} / \mathrm{L})$, mean particle size distribution dropped by $81.85 \%(27.17 \mu \mathrm{m}$ to $4.93 \mu \mathrm{m})$ and colour by $88 \%(0.86$ to 0.10$)$. Zeta potential of treated effluent was at -24.2 suggesting high content of ions in the solution that is also confirmed by the high conductivity of $8.23 \mathrm{mS} / \mathrm{cm}$ and a $\mathrm{pH}$ of 7.83 . In terms of content, the treated effluent is found containing VFA $2.65 \mathrm{~g} / \mathrm{L}$, ammonia $0.96 \mathrm{~g} / \mathrm{L}$ and phosphate of $1.91 \mathrm{~g} / \mathrm{L}$ at a $\mathrm{pH}$ of 7.83 . These components can successfully be used by microorganisms as growth stimulants (nitrogen, carbon and hydrogen intake). However, the solid matter content and the ions related measures indicate a solution rich in mineral salts that may be uptaken during the microbial metabolism. E.coli is a well known industrially relevant strain, that has been utilised for production of vaccines, enzymes, natural acidifiers and biofuels [12]. A fully grown on LB broth inoculum of Ecoli $\left(\mu_{\max } 0.6 \mathrm{~h}^{-1}\right.$, td $1.15 \mathrm{~h}$ ) was propagated in the treated effluent achieving a $\mu_{\max }$ of $0.65 \mathrm{~h}^{-1}$ and a td of 1.06 supporting fastidious growth at a slightly improved rate than the in vitro medium. On the other hand, when E.coli is grown in minimised media (autoclaved tap water mixed with $0.11 \mathrm{M}$ of glucose) $\mu_{\max }$ is dropping to a $0.02 \mathrm{~h}^{-1}$ and a td of $38.2 \mathrm{~h}$, suggesting that E.coli cannot successfully grow in limited conditions. To achieve higher $\mu_{\max }$ treated effluents were enriched with $0.11 \mathrm{M}$ glucose broth achieving $\mu_{\max } 1.31 \mathrm{~h}^{-1}$ and a td of $0.52 \mathrm{~h}$ suggesting a strong potential in using the complex effluents of a ratio of $\mathrm{N}: \mathrm{P}$ 36.6:1 either solely or enriched with carbohydrate sources for growth of microorganism (Figure 2).

Possibly, microorganisms whose end products are susceptible to genetic mutations such as enzymes or proteins might not be suitable for such applications, bacteria or fungi though with metabolic products such as acids or biofuels like ethanol can be used safely. 


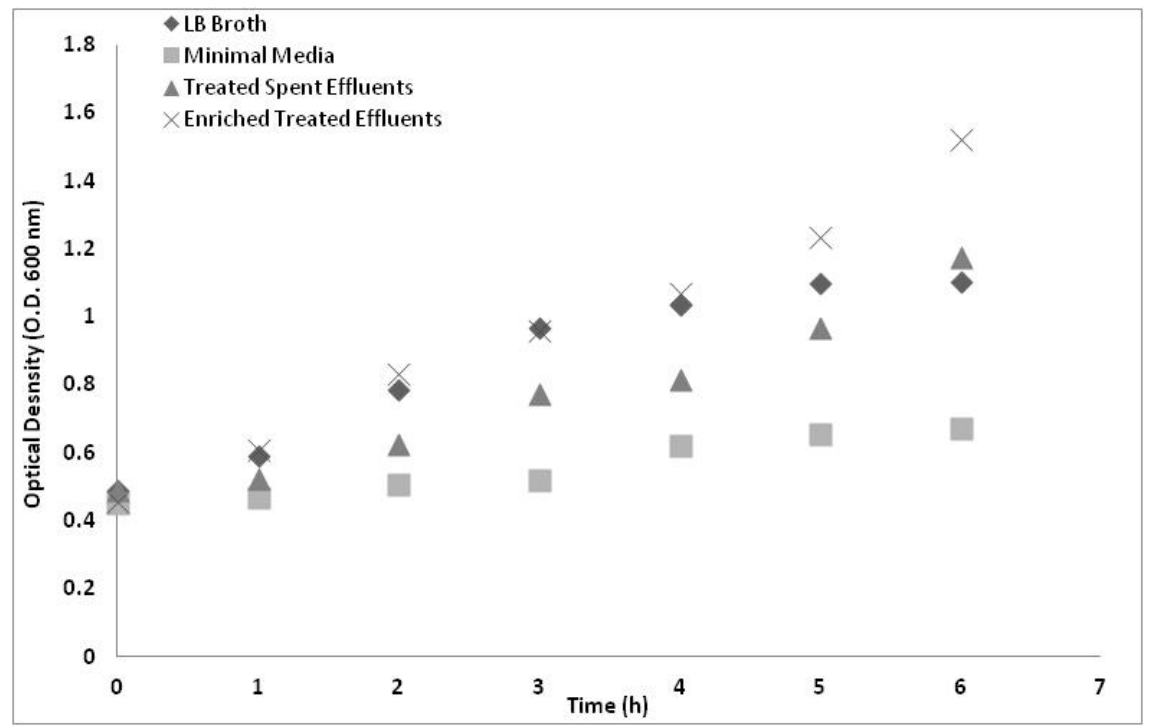

Figure 2: $\quad$ Growth of E.coli on different nutrient sources.

Interestingly decolourisation was observed when E.coli was grown of the treated effluents resulting to an optical density of 0.02 , a reduction of $80 \%$, suggesting that this microorganism might serve as a bioremediation agent.

Regardless, the encouraging results of these methodologies and there adoption on the large scale is strongly dependent on their economic application [10]. It has been estimated that the cost of treatment per cubic meter of spent digester effluents rises up to $£ 0.91$ and $1.04 \mathrm{kWh}$ of energy [10]. These could be potentially reduced after optimisation of operational conditions.

\section{Conclusions}

This study investigates spent digester fluids and developing a recovery strategy solely devoted on the recovery of VFA, phosphate, ammonia from anaerobic digestates, might not be as easy as from an acidogenic digester where the VFA concentration will be substantially higher, up to $200 \mathrm{mM}$. It has been pointed out that farming waste effluents do represent an environmental hazard as well as a good source virtually in abundance of useful nutrients and metals. Developing a complete recovery strategy for these substances, with a waste treatment system placed in situ could be of great benefit for the industry.

Filtration can be used as a method of isolation and recovery of nutrients from complex effluent streams, provided a pre-treatment scheme that will remove coarse particles, so the effluents can be easily filtered.

These findings show potential and could be applied to the biotechnological production of a range of products from these waste raw materials. 


\section{Acknowledgement}

This project was supported by Low Carbon Research Institute (LCRI) project grant title "Wales H2 Cymru".

\section{References}

[1] A. Dimakis, M. Biberacher, J. Dominguez, G. Fiorese, S. Gadocha, E. Gnansounou, G. Guariso, A. Kartalidis, L. Panichelli, I. Pinedo, M. Robba, Methods and tools to evaluate the availability of renewable energy sources, Renewable Sustainable Energy Reviews, 15, 1182-1200, 2011.

[2] M. Jefferson, Accelerating the transition to sustainable energy systems, Energy Policy, 36, 4116-4125, 2008.

[3] P.A. Østergaard, Comparing electricity, heat and biogas storages' impacts on renewable energy integration, Energy, 37, 255-262, 2012.

[4] L. Appels, J. Baeyens, J. Degrève, R. Dewil, Principles and potential of the anaerobic digestion of waste-activated sludge, Progress in Energy Combustion. Science, 34, 755-781, 2008.

[5] E.A. Salminen, J. A. Rintala, Semi-continuous anaerobic digestion of solid poultry slaughterhouse waste: effect of hydraulic retention time and loading, Water Research, 36, 3175-3182, 2002.

[6] M.P. Zacharof, R.W. Lovitt, The use of mixed effluent liquid wastes as a source of valuable nutrients. Waste Management and the Environment $V$, WIT Press, 335-342, 2012.

[7] M. P. Zacharof, R.W. Lovitt, Use of complex effluent streams as a potential source of Volatile Fatty acids (VFA) - A review article. The 4th International Conference on Engineering for Waste and Biomass Valorisation (WasteEng12), Porto, WasteEng Conference Series, 2012.

[8] M.P. Zacharof and R. W. Lovitt, Recovery of volatile fatty acids (VFA) from complex waste effluents using membranes, Water Science and Technology (Article In Press) DOI: 10.2166/wst.2013.717, 2013.

[9] M.P. Zacharof and R. W. Lovitt, Complex effluent streams as a potential source of volatile fatty acids, Waste and Biomass Valorisation, 4, 557-581, 2013.

[10] M.L. Gerardo, M.P. Zacharof, R. W. Lovitt, Strategies for the recovery of nutrients and metals from anaerobically digested from dairy farm sludge using cross-flow microfiltration, Water Research, 47, 4833-4842, 2013.

[11] M.P. Zacharof and R. W. Lovitt Modelling and simulation of cell growth dynamics, substrate consumption and lactic acid production kinetics of Lactococcus lactis, Biotechnology and Bioengineering, DOI: 10.1007/s12257-012-0477-4, 2012.

[12] H. Danner and R. Braun Biotechnology for the production of commodity chemicals from biomass, Chemical. Society Reviews, 28, 395-405, 1999. 